\title{
Design of a Compact UWB Bandpass Filter using Via-Less CRLH TL
}

\author{
${ }^{1}$ Dileep Kumar Upadhyay, ${ }^{2}$ Uday Kumar, ${ }^{3}$ Gajendra Kant Mishra \\ ${ }^{1,2,3}$ Department of Electronics and Communication Engineering, Birla Institute \\ of Technology, Mesra,Ranchi, India \\ Emails: 'dileep_bit@yahoo.com \\ ${ }^{2}$ ranjanuday333@gmail.com \\ 3 gkmishra@bitmesra.ac.in \\ ${ }^{4}$ Babu Lal Shahu \\ ${ }^{4}$ Department of Electronics and Communication Engineering, Birla Institute of \\ Technology, Mesra, Deoghar Campus, Deoghar-814142, India \\ Email: ${ }^{4}$ sahu.babulal@gmail.com
}

\begin{abstract}
A novel compact ultra wideband (UWB) bandpass filter (BPF) based on composite right/left handed transmission line (CRLH TL) is reported in this paper. The proposed UWB BPF is designed and developed by coupling of two unit-cells of via-less CRLH TL, excited by asymmetrical coplanar waveguide (CPW) feed-line. The unit cell of CRLH TL is designed using series interdigital capacitor (IDC) in shunt with the shorted inductive stub. Because of the CPW-fed, no via is required to get the shunt inductance for the realization of CRLH TL, which minimizes the fabrication steps. The filter is compact in size $11.9 \times 6 \mathrm{~mm}^{2}$. The proposed filter exhibits the return-loss $\left(\left|S_{11}\right|\right)$ more than $11.2 \mathrm{~dB}$ and insertion-loss $\left(\left|S_{21}\right|\right)$ less than $0.5 \mathrm{~dB}$ and low and flat group delay response throughout the passband, $3.3 \mathrm{GHz}$ to $13.0 \mathrm{GHz}$. The proposed UWB BPF also shows the good stopband rejection $\left(\left|S_{21}\right|>\right.$ $20 \mathrm{~dB}$ and $\left|\mathrm{S}_{11}\right|<0.8 \mathrm{~dB}$ ) from $13.6 \mathrm{GHz}$ to $15 \mathrm{GHz}$ and steep roll-off from passband to stopband. The fractional bandwidth (FBW) of the filter is found to be $119 \%$. The equivalent lumped circuit model of the filter is obtained through Ansoft Designer. All simulated results are extracted through method of moment based simulator, IE3D. Agilent vector network analyzer (VNA) is used to get the measured results. All measured results are found in close similarity with the simulated results.
\end{abstract}

Index Terms - Composite right/left handed transmission line, Interdigital capacitor, Ultra wideband bandpass filter.

\section{INTRODUCTION}

The left handed metamaterials can be realized mainly by two methods, firstly, using periodic arrangement of split ring resonators and thin metallic wires and, secondly by dual of conventional right handed transmission line, i.e. by periodic arrangement of series interdigital capacitors in shunt with the shorted stubs to ground. The first and second methods are respectively known as resonant and non-resonant approach of realization of left handed metamaterials. Due to large in size and lossy in nature, the resonant approach is not well suited for the realization of left handed metamaterials [1]. Since 2002 the U.S. Federal Communications Commission (FCC) [2] has regularized the unlicensed use of UWB frequency band 31 . GHz to $10.6 \mathrm{GHz}$, the research in the field of UWB bandpass filter 
has gained much attention and challenges. The design of ultra wideband components need much efforts and attentions as it requires the good selectivity, low insertion-loss and low and constant group delay throughout the passband.

The UWB BPF reported in [3] is based on conventional CRLH TL designed by using via. The reported UWB BPF in [3] has good S-parameters characteristics and compact in size (16.4 x 4.8 $\mathrm{mm}^{2}$ ). Moreover because of the use of via it requires the extra fabrication processing steps for drilling and soldering as compared to the proposed UWB BPF. The UWB bandpass filter presented in [4] is based on defected ground structure (DGS) as split ring resonator and conventional CRLH TL with via. The reported filter [4] is compact in size, $13 \times 8.5 \mathrm{~mm}^{2}$, however because of the split ring resonator structure in ground plane and the presence on via, it requires the more extra efforts in ground plane processing and for creation of via. A single CRLH TL cell based UWB band pass filter [5] operating over the frequency band of $4 \mathrm{GHz}$ to $9.5 \mathrm{GHz}$ is of relatively large in size, $30 \times 8.5 \mathrm{~mm}^{2}$ and also requires the via for the realization of CRLH TL. The reported filter [5] also suffers with the poor S-parameters performance in passband $\left(\left|\mathrm{S}_{21}\right|=1.5 \mathrm{~dB}\right)$ as well as in stopband. A compact UWB band pass filter $\left(18.4 \times 4.5 \mathrm{~mm}^{2}\right)$ reported in [6] has good S-parameters performance $\left(\left|\mathrm{S}_{21}\right|<0.3 \mathrm{~dB}\right.$ and $\left|S_{11}\right|>10 \mathrm{~dB}$ ) is designed on via-less CRLH TL. Moreover the reported UWB BPF [6] operated over relatively low frequency band $3.1 \mathrm{GHz}$ to $10.6 \mathrm{GHz}$ and relatively large in size as compared to the proposed UWB BPF ( frequency band, $3.3 \mathrm{GHz}$ to $13.0 \mathrm{GHz}$ and size, $11.9 \times 6 \mathrm{~mm}^{2}$ ). An ultra wideband band pass filter designed using interdigitated coupled lines CRLHTL structure [7] operated over $3.9 \mathrm{GHz}$ to $10.3 \mathrm{GHz}$ is relatively large in size $\left(30 \mathrm{x} 15 \mathrm{~mm}^{2}\right)$, requires the generation of via and suffers with relatively poor insertion loss $\left(\left|\mathrm{S}_{21}\right|=1.5 \mathrm{~dB}\right)$.

Many researchers and scientists worldwide have investigated, designed and developed various UWB BPFs based on different techniques such as; by use of fractal geometry, defected ground plane, coupled line structure and multimode resonator etc. References [8-13] report the various UWB BPFs based on different techniques such as a CRLH TL and fractal geometry based UWB BPF [8], the coupled structure based ultra wideband bandpass filter [9], defected ground structure [10], modified CRLH TL with cross coupling [11], cascading bandpass and bandstop filters [12] and multi mode resonator based UWB BPF [13]. The UWB BPFs [8-13] designed using different techniques are considered in this paper for comparison of various parameters with the proposed UWB BPF.

In this paper design and development of a compact $\left(11.9 \times 6 \mathrm{~mm}^{2}\right)$ ultra wideband bandpass filter based on via-less CRLH TL is reported. Since in CPW-fed, the signal plate and ground plate both reside on the top plane of the dielectric substrate, hence no via is required for the realization of proposed CRLH TL, in contrast to conventional design of CRLH TL, where, via is required to short circuit the shunt inductive stub to ground. The absence of via reduces the fabrication steps, saves the valuable time wastage and minimizes the overall bulk production cost. The proposed UWB BPF is designed by coupling between two similar unit-cells of CRLH TL. The unit-cell of CRLH TL is designed by series five fingers based interdigital capacitor in shunt with the inductive stub shorted to 
the one of the ground plane of CPW feed-line. The filter exhibits the return-loss greater than $11.2 \mathrm{~dB}$ and insertion-loss less than $0.5 \mathrm{~dB}$ to whole passband frequency range, $3.3 \mathrm{GHz}$ to $13 \mathrm{GHz}$, with steep roll-off during the transition from stopband to passband and stopband rejection level greater than $20 \mathrm{~dB}$ for frequency range of $13.3 \mathrm{GHz}$ to $15 \mathrm{GHz}$. The filter shows the low (maximum variation of $0.8 \mathrm{~ns}$ ) and constant group delay throughout the passband. The proposed UWB BPF is designed and developed on RT/duroid dielectric substrate with relative permittivity of 2.2 , thickness of 1.57 $\mathrm{mm}$ and loss-tangent of 0.0009 . The equivalent lumped circuit model of the proposed filter is obtained using circuit model tool of Ansoft Designer. The simulation and measured results are obtained from electromagnetic (EM) simulator, IE3D and vector network analyzer respectively. All measured results are found in close similarity with the simulated results.

\section{THEORY AND DESIGN OF PROPOSED UWB BANDPASS FILTER}

The composite right/left handed transmission line can be realized by dual of conventional right handed transmission line (RH TL), known as non-resonant approach. The pure right handed transmission line (PRH TL) consists of series inductor in shunt with the capacitor, whereas pure left handed transmission line (PLH TL) is realized by series capacitor in shunt with the inductor. Unfortunately, either PRH TL or PLH TL cannot be physically realized because of the unavoidable parasitic effects of microstrip transmission lines. Hence because of the unavoidable parasitic effects, the CRLH TL is realized rather than the PRH TL. The CRLH TL shows the virtue of both, the nature of left handed transmission line (LH TL) at low frequencies and the nature of RH TL at high frequencies [1].

The unit-cell of CRLH TL consists of per-unit series LH capacitance $\left(C_{L H}\right)$ and per-unit right handed inductance $\left(L_{R H}\right)$ and per-unit shunt LH inductance $\left(L_{L H}\right)$ and per-unit RH capacitance $\left(C_{R H}\right)$. The combination of series RH inductance $\left(L_{R H}\right)$ and shunt RH capacitance $\left(C_{R H}\right)$ in CRLH $\mathrm{TL}$ works as a lowpass filter whose cut-off frequency is given as $f_{C R}=\frac{1}{2 \pi \sqrt{L_{R H} C_{R H}}}$. The combination of series LH capacitance $\left(C_{L H}\right)$ and shunt LH inductance $\left(L_{L H}\right)$ in CRLH TL works as a highpass filter whose cut-off frequency is given as $f_{C L}=\frac{1}{2 \pi \sqrt{L_{L H} C_{L H}}}$. So, when $f_{C R}<f_{C L}$, the CRLH TL works as a wideband bandpass filter.

The series, $f_{S E}$ and shunt, $f_{S H}$ resonance frequencies of the CRLH TL are given as follows

For balanced CRLH TL,

$$
\begin{gathered}
f_{S E}=\frac{1}{2 \pi \sqrt{L_{R H} C_{L H}}} \\
f_{S H}=\frac{1}{2 \pi \sqrt{L_{L H} C_{R H}}}
\end{gathered}
$$

$$
f_{S E}=f_{S H}=f_{C}=\sqrt{f_{S E} f_{S H}}
$$


Where, $f_{C}$ is known as centre frequency. The lower end, $f_{L}$ and upper end, $f_{U}$ frequencies of CRLH $\mathrm{TL}$ are given as follows

$$
\begin{aligned}
f_{L} & =\frac{1}{2 \pi \sqrt{L_{R H} C_{L H}}} \\
f_{U} & =\frac{1}{2 \pi \sqrt{L_{R H} C_{L H}}}
\end{aligned}
$$

The design layout of proposed ultra wideband bandpass filter with the notation of all physical dimensions is depicted in Fig.1. The filter is excited by asymmetrical CPW-fed, which consists of two ground planes. As shown in Fig. 1, UWB BPF is designed using coupling of two symmetrical series interdigital capacitors (IDC). The IDC consists of five fingers of finger length $L_{3}$, finger width $S_{2}$ and finger spacing $S_{1}$. The coupling gap between the two IDCs is $S_{6}$. The two stubs each of length $L_{9}$, is connected to each IDC and ground plane 2 to get the shunt inductance. Since signal plane and ground plane both are in same planes, hence no via is required to short circuit the stubs to ground plane 2 , in contrast to the conventional method of design of CRLH TL with via. The absence of via minimizes the fabrication steps, saves the fabrication time and reduces the overall bulk production cost. The filter is compact in size, $11.9 \times 6 \mathrm{~mm}^{2}$.

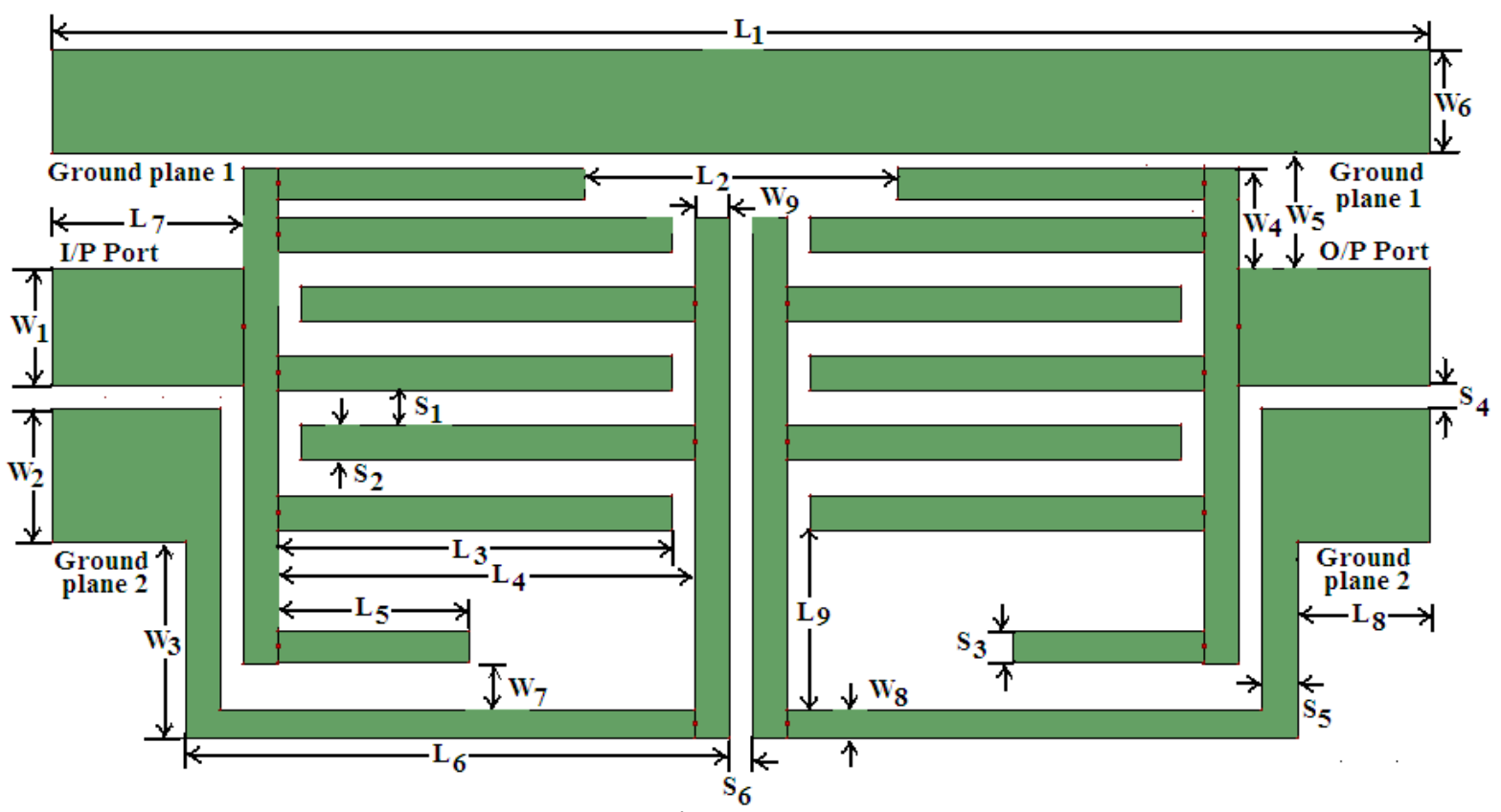

Fig. 1. Design layout of the proposed ultra wideband bandpass filter

\section{EFFECTS OF VARIATION OF VARIOUS PHYSICAL PARAMETERS ON UWB BPF}

All optimized physical dimensions of the proposed UWB BPF are obtained by parametric study of the geometry shown in Fig.1. The nature of variation of S-parameters characteristics of filter is investigated and analyzed for variation on one physical parameter keeping other parameters constant, to get the best optimized physical dimensions of the geometry, which can meet the low insertion-loss and return-loss better than $10 \mathrm{~dB}$ throughout the passband. 


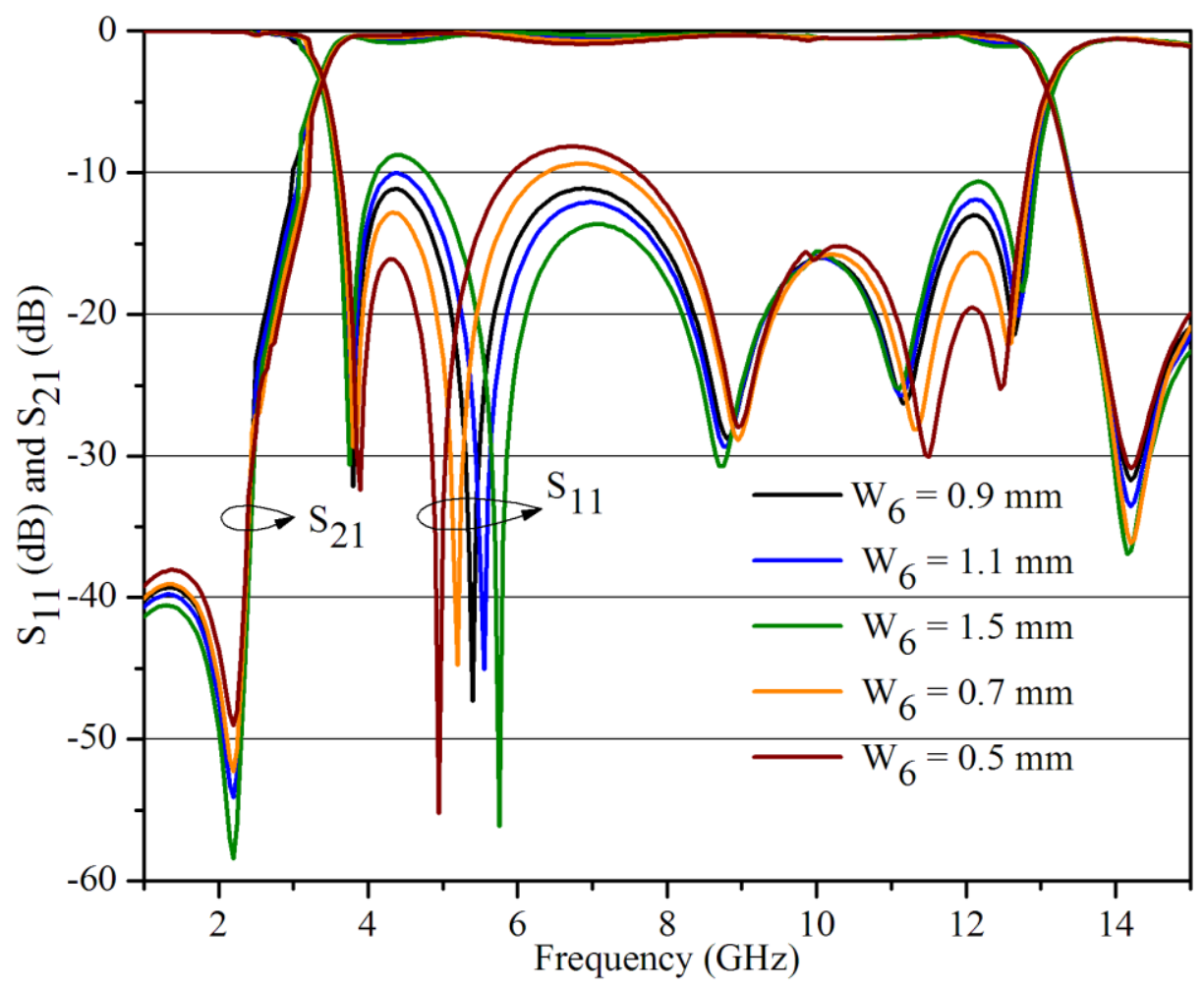

Fig. 2. S-parameters vs. Frequency plot for the variation of parameter $\mathrm{W}_{6}$

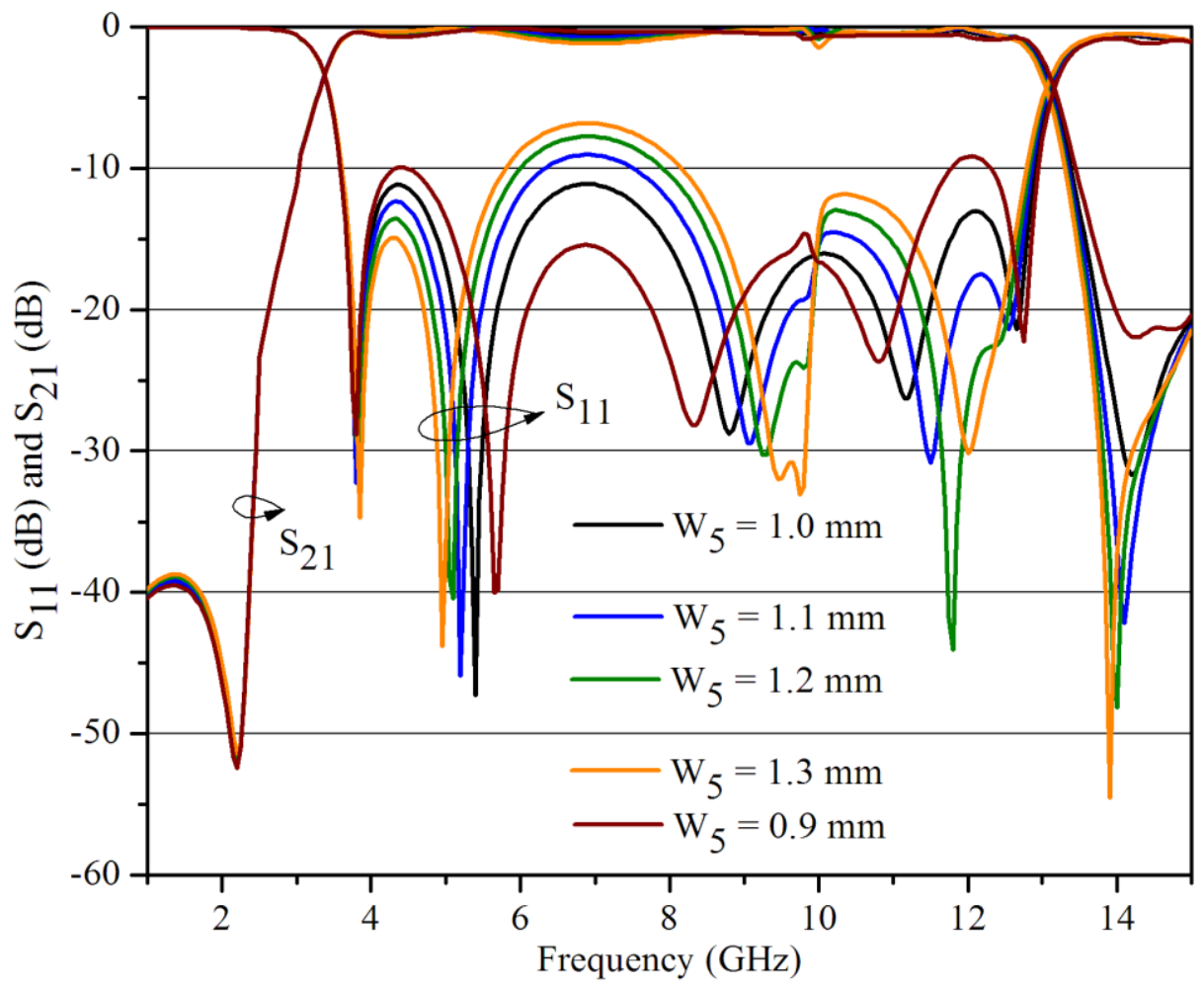

Fig. 3. S-parameters vs. Frequency plot for the variation of parameter $\mathrm{W}_{5}$

The effects of variation of physical parameter $\mathrm{W}_{6}$ is shown in Fig. 2. The optimum value of $\mathrm{W}_{6}$ is taken to be $0.9 \mathrm{~mm}$. It can be seen from Fig. 2 that as the value of $\mathrm{W}_{6}$ is increased from $0.9 \mathrm{~mm}$ to 1.5 $\mathrm{mm}$, the S-parameters improve in frequency band $6.0 \mathrm{GHz}$ to $8.0 \mathrm{GHz}$ and deteriorate in the frequency band of $4 \mathrm{GHz}$ to $4.8 \mathrm{GHz}$ and $11.7 \mathrm{GHz}$ to $12.4 \mathrm{GHz}$ for the constant bandwidth $3.3 \mathrm{GHz}$ 
to $13.0 \mathrm{GHz}$. As the value of $\mathrm{W}_{6}$ is decreased from $0.9 \mathrm{~mm}$ to $0.5 \mathrm{~mm}$, the value of S-parameters deteriorate in frequency band $6.0 \mathrm{GHz}$ to $8.0 \mathrm{GHz}$ and improve in $4 \mathrm{GHz}$ to $4.8 \mathrm{GHz}$ and $11.7 \mathrm{GHz}$ to 12.4 GHz. So the value of $\mathrm{W}_{6}$ is considered as $0.9 \mathrm{~mm}$ by compromising the performance in passband. The sensitivity for the variation of physical parameter, $\mathrm{W}_{5}$ on $\mathrm{S}$-parameters versus frequency plot is shown in Fig. 3. As the value of $\mathrm{W}_{5}$ increases from $1.0 \mathrm{~mm}$ to $1.3 \mathrm{~mm}$, the $\mathrm{S}$ parameters performance deteriorate in frequency band $6.0 \mathrm{GHz}$ to $8.0 \mathrm{GHz}$ and improve in the frequency band $4 \mathrm{GHz}$ to $4.8 \mathrm{GHz}$. The vice-versa effects can be seen for the value of $\mathrm{W}_{5}$ less than $1.0 \mathrm{~mm}$. Hence the optimized value of $\mathrm{W}_{5}$ is chosen to be $1.0 \mathrm{~mm}$, by considering the performance of $\mathrm{S}$-parameters in both bands. For the variation of $\mathrm{W}_{5}$, the overall bandwidth remains almost constant, i.e. from $3.3 \mathrm{GHz}$ to $13.0 \mathrm{GHz}$. The effects of variation of physical parameters $\mathrm{L}_{2}$ on $\mathrm{S}$-parameters versus frequency plot is depicted in Fig. 4. Considering the response of S-parameters in the band 4.0 $\mathrm{GHz}$ to $8.0 \mathrm{GHz}$ and $11.7 \mathrm{GHz}$ to $12.4 \mathrm{GHz}$, the optimum value of $\mathrm{L}_{2}$ is considered as $2.7 \mathrm{~mm}$.

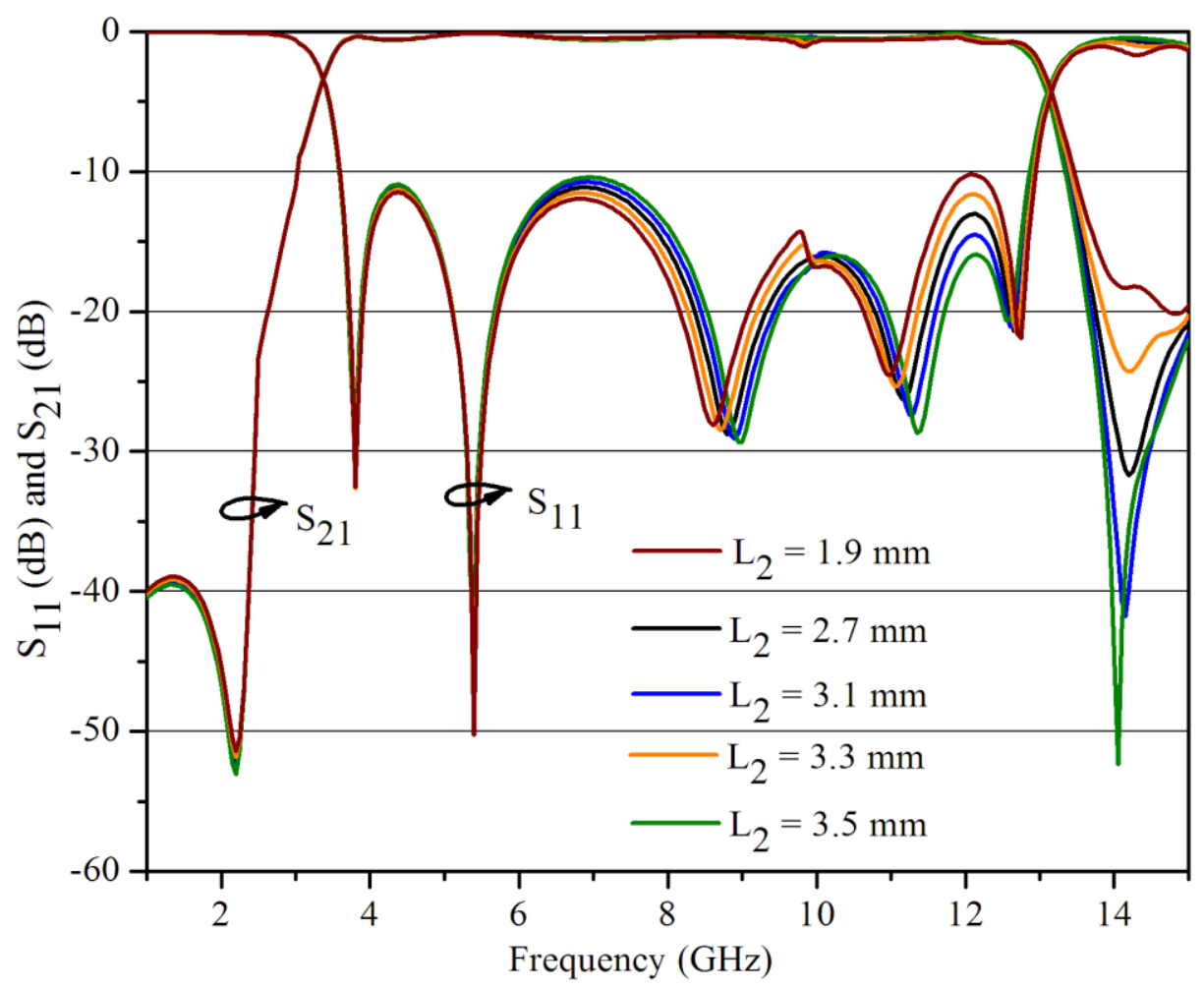

Fig. 4. S-parameters vs. Frequency plot for the variation of parameter $\mathrm{L}_{2}$

The sensitivity for the variation of physical parameter $\mathrm{L}_{9}$ on $\mathrm{S}$-parameters response is shown in Fig. 5. The optimized value of $\mathrm{L}_{9}$ is considered to be $1.6 \mathrm{~mm}$. As the value of $\mathrm{L}_{9}$ increases from $1.6 \mathrm{~mm}$ to $2.2 \mathrm{~mm}$, the S-parameters performance deteriorate in the frequency bands $6.0 \mathrm{GHz}$ to $8.0 \mathrm{GHz}$ and 4.0 $\mathrm{GHz}$ to $4.8 \mathrm{GHz}$ and improve in the frequency bands $9.0 \mathrm{GHz}$ to $11.0 \mathrm{GHz}$ and $11.7 \mathrm{GHz}$ to 12.4 GHz. For the value of $\mathrm{L}_{9}$ less than $1.6 \mathrm{~mm}$, the vice-versa effects are observed in all considered bands. The S-parameters versus frequency plot for the variation of physical parameter $L_{5}$ is shown in Fig. 6. Considering the performance of S-parameter throughout the passband, the value of $L_{5}$ is chosen to be $1.65 \mathrm{~mm}$. As the value of $\mathrm{L}_{5}$ increases $1.65 \mathrm{~mm}$ to $2.25 \mathrm{~mm}$, the high end frequency 
shifted from $13.0 \mathrm{GHz}$ to $12.5 \mathrm{GHz}$ and S-parameters deteriorate in the frequency band $11.7 \mathrm{GHz}$ to 12.4 GHz. For the lower values of $\mathrm{L}_{5}$, the high end frequency shifted from $13.0 \mathrm{GHz}$ to $13.5 \mathrm{GHz}$, but S-parameters response slightly deteriorate in frequency bands $6.0 \mathrm{GHz}$ to $8.0 \mathrm{GHz}$ and $4.0 \mathrm{GHz}$ to 4.8 $\mathrm{GHz}$.

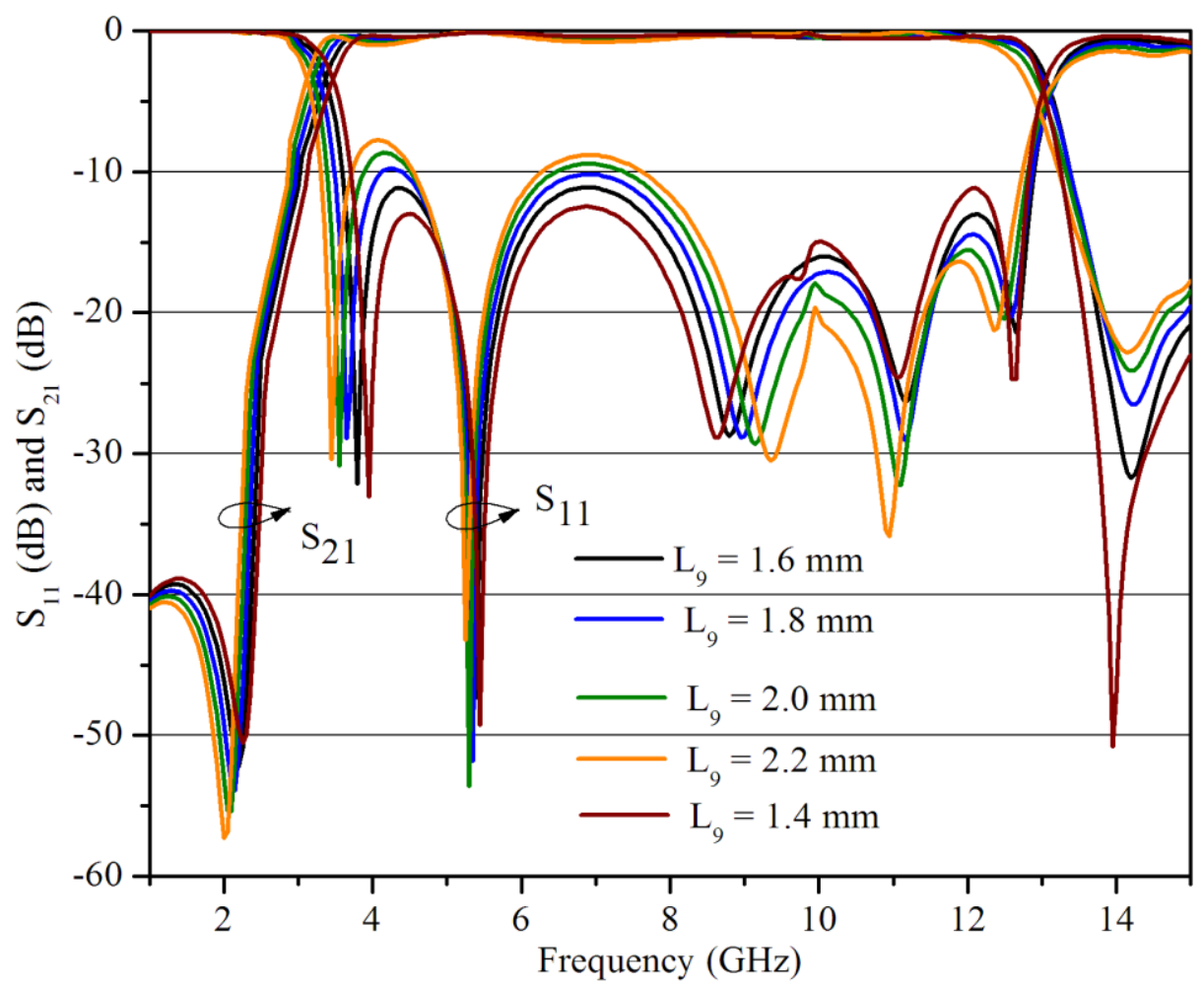

Fig. 5. S-parameters vs. Frequency plot for the variation of parameter $\mathrm{L}_{9}$

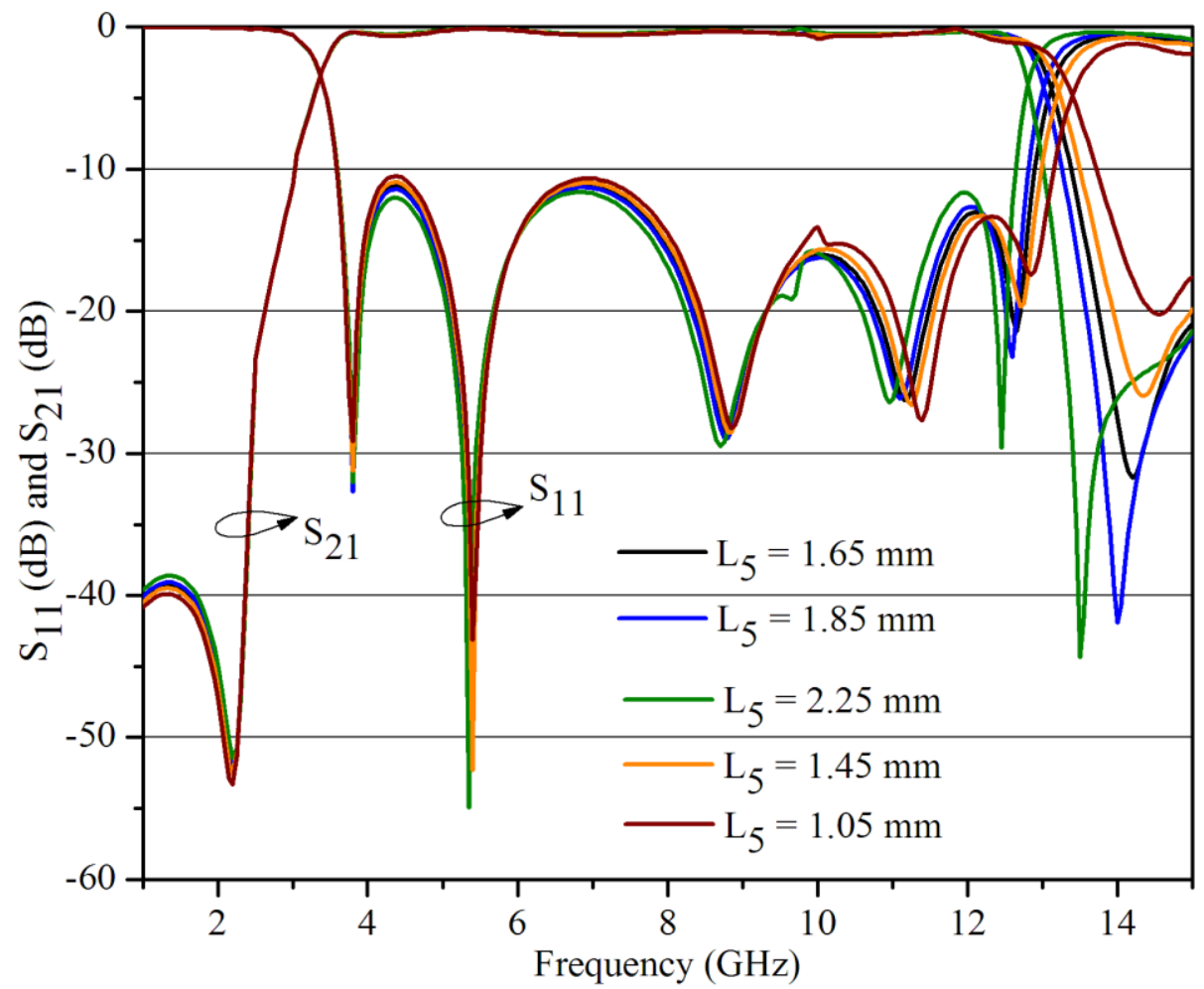

Fig. 6. S-parameters vs. Frequency plot for the variation of parameter $\mathrm{L}_{5}$ 


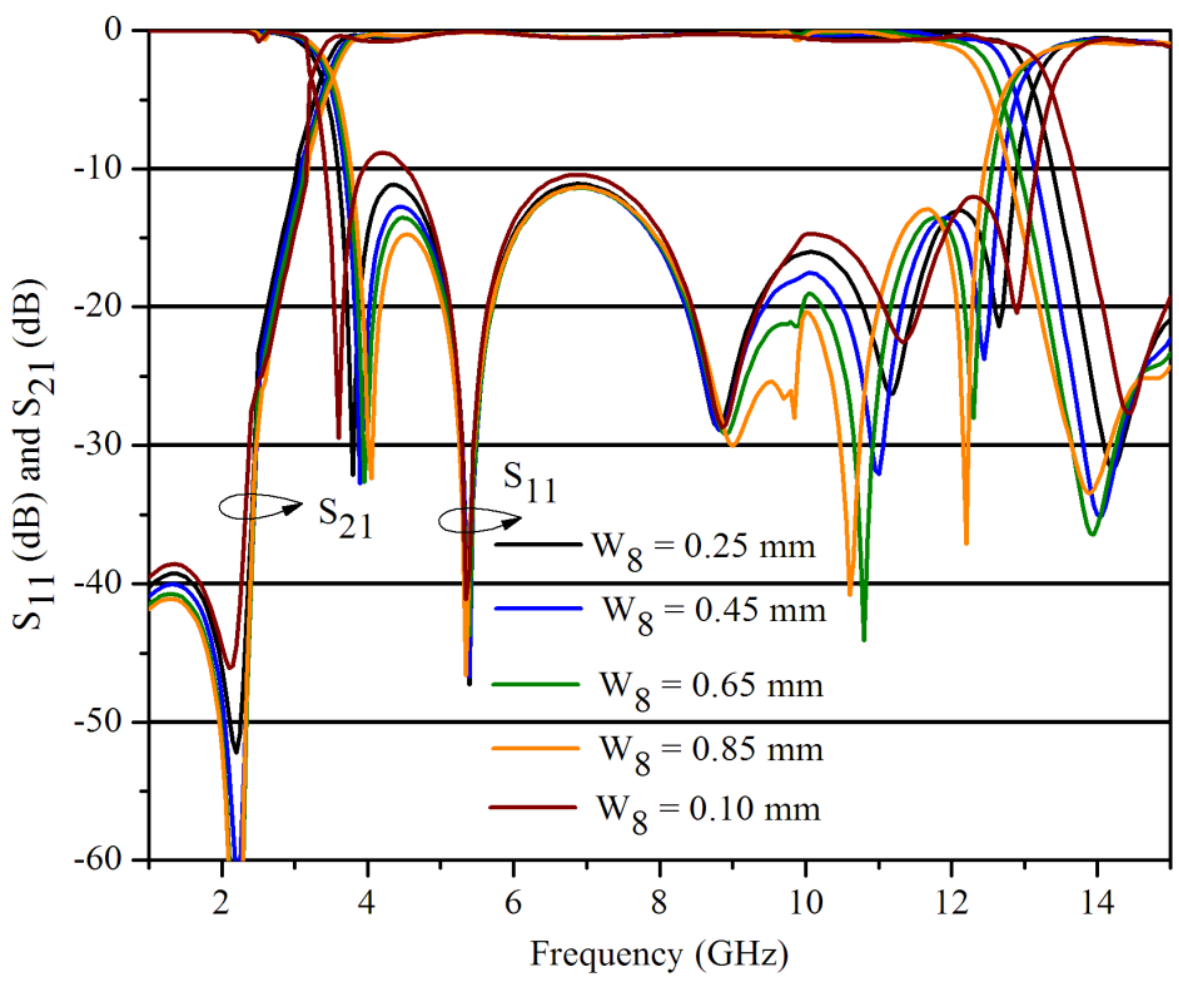

Fig. 7. S-parameters vs. Frequency plot for the variation of parameter $\mathrm{W}_{8}$

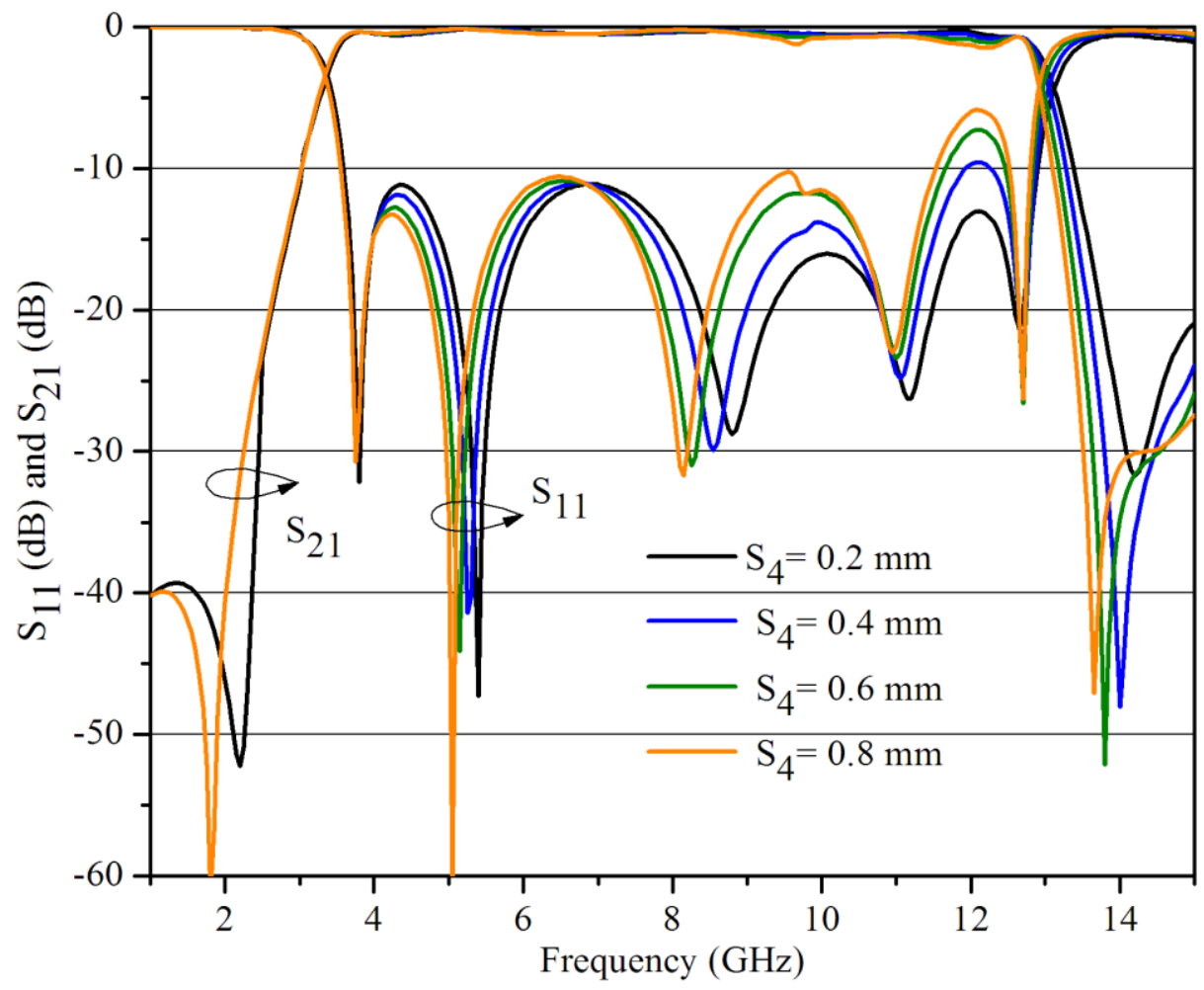

Fig. 8. S-parameters vs. Frequency plot for the variation of parameter $\mathrm{S}_{4}$

The effects on S-parameters response for the change of width of ground plane $2, \mathrm{~W}_{8}$ is illustrated in Fig. 7. The optimum value of $\mathrm{W}_{8}$ is considered as $0.25 \mathrm{~mm}$. From the Fig. 7, it can be observed that by increasing the value of $\mathrm{W}_{8}$ from $0.25 \mathrm{~mm}$ to $0.85 \mathrm{~mm}$, the S-parameters improve in passband but at the same time the high end frequency decreases from $13 \mathrm{GHz}$ for the case of $\mathrm{W}_{8}=0.25 \mathrm{~mm}$ to 12.4 
$\mathrm{GHz}$ for the case of $\mathrm{W}_{8}=0.85 \mathrm{~mm}$. The shift in high end frequency to the lower end, decreases the overall bandwidth, which is not desirable. Decreasing the value of $\mathrm{w}_{8}$ from $0.25 \mathrm{~mm}$ to $0.1 \mathrm{~mm}$ the overall bandwidth increases, but the passband S-parameters performance become poor. The effect on S-parameters response for the variation of physical parameter $\mathrm{S}_{4}$, is depicted in Fig. 8. Changing the value of $\mathrm{S}_{4}$, the overall bandwidth remains almost unchanged. By increasing the value of $\mathrm{S}_{4}$ from 0.2 $\mathrm{mm}$ to $0.8 \mathrm{~mm}$, the S-parameters performance of the filter deteriorates in passband. Hence, the optimum value of $S_{4}$ is chosen to be $0.2 \mathrm{~mm}$. The effects of variation of the coupling gap $S_{6}$, between the two interdigital capacitors on S-parameters performance is illustrated in Fig. 9. Increasing the value of $\mathrm{S}_{6}$ from $0.2 \mathrm{~mm}$ to $0.8 \mathrm{~mm}$, the $\mathrm{S}$-parameters performance and overall bandwidth of the filter remain almost invariant. For zero gap between the two interdigital capacitors $\left(S_{6}=0.0 \mathrm{~mm}\right)$, the return-loss and insertion-loss deteriorate by considerable amount. Hence, an optimum value of $\mathrm{S}_{6}$ is considered as $S_{6}=0.2 \mathrm{~mm}$. For others value of physical parameters, similar parametric studies discussed for Fig. 2 to Fig. 9 are performed and their optimum values are found. Similar to parametric studies performed and depicted from Fig. 2 to Fig. 9. The various optimized physical dimensions of the proposed UWB BPF is listed in Table I.

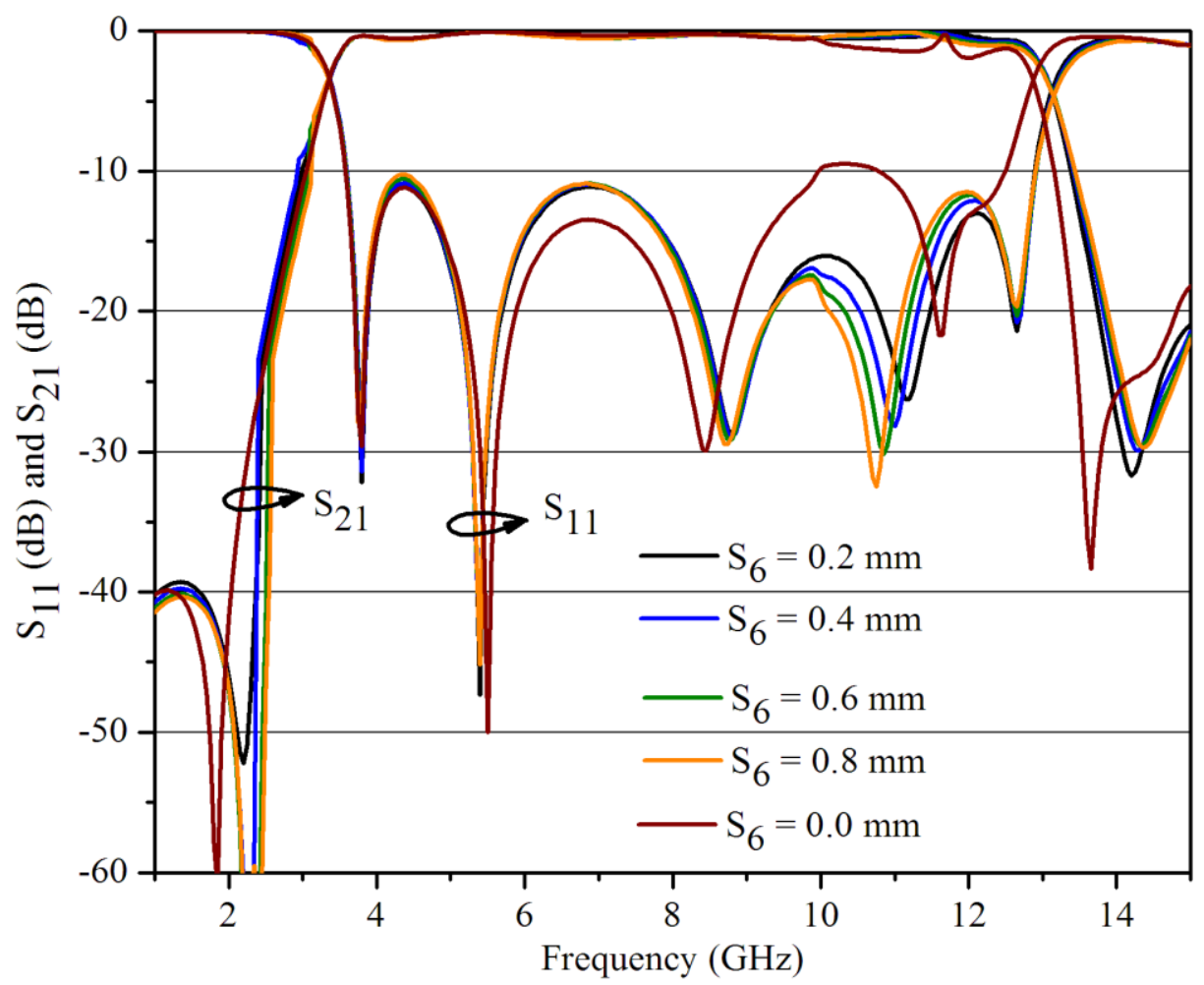

Fig. 9. S-parameters vs. Frequency plot for the variation of parameter $S_{6}$ 
TABLE I. OPTIMIZED PHYSICAL PARAMETERS OF PROPOSED UWB BPF SHOWN IN FIG. 1

\begin{tabular}{|c|c|c|c|c|c|c|c|c|}
\hline Parameter & $\mathrm{L}_{1}$ & $\mathrm{~L}_{2}$ & $\mathrm{~L}_{3}$ & $\mathrm{~L}_{4}$ & $\mathrm{~L}_{5}$ & $\mathrm{~L}_{6}$ & $\mathrm{~L}_{7}$ & $\mathrm{~L}_{8}$ \\
\hline $\begin{array}{c}\text { Dimension } \\
(\mathrm{mm})\end{array}$ & 11.9 & 2.7 & 3.4 & 3.6 & 1.65 & 4.7 & 1.65 & 1.15 \\
\hline Parameter & $\mathrm{L}_{9}$ & $\mathrm{~W}_{1}$ & $\mathrm{~W}_{2}$ & $\mathrm{~W}_{3}$ & $\mathrm{~W}_{4}$ & $\mathrm{~W}_{5}$ & $\mathrm{~W}_{6}$ & $\mathrm{~W}_{7}$ \\
\hline $\begin{array}{c}\text { Dimension } \\
(\mathrm{mm})\end{array}$ & 1.6 & 1.0 & 1.15 & 1.7 & 0.87 & 1.0 & 0.9 & 0.4 \\
\hline Parameter & $\mathrm{W}_{8}$ & $\mathrm{~W}_{9}$ & $\mathrm{~S}_{1}$ & $\mathrm{~S}_{2}$ & $\mathrm{~S}_{3}$ & $\mathrm{~S}_{4}$ & $\mathrm{~S}_{5}$ & $\mathrm{~S}_{6}$ \\
\hline $\begin{array}{c}\text { Dimension } \\
(\mathrm{mm})\end{array}$ & 0.25 & 0.3 & 0.3 & 0.3 & 0.27 & 0.2 & 0.3 & 0.2 \\
\hline
\end{tabular}

IV. EQUIVALENT LUMPED CIRCUIT MODEL ANALYSIS

The equivalent lumped circuit mode of the proposed UWB BPF shown in Fig. 1 is depicted in Fig. 10. The equivalent lumped circuit model results are obtained using circuit model tool of the Ansoft Designer. Considering the layout of the proposed UWB BPF, an equivalent circuit diagram is designed. The lumped element values are manually optimized by changing the each element value so that it can have the good agreement with the simulated results obtained from the full wave simulator. In the lumped equivalent circuit diagram, the mutual coupling between the individual elements is not taken in to consideration. The inductive components, $\mathrm{L}_{1}$ and $\mathrm{L}_{2}$ are generated because of the input and output CPW-fed transmission lines. The left handed capacitors, $\mathrm{C}_{\mathrm{LH} 1}$ and $\mathrm{C}_{\mathrm{LH} 2}$ are introduced because of the input and output interdigital capacitors. The right handed inductances, $\mathrm{L}_{\mathrm{RH} 1}$ and $\mathrm{L}_{\mathrm{RH} 2}$ are included because of the parasitic effects in input and output IDCs. The shunt left handed inductances $\mathrm{L}_{\mathrm{LH} 11}, \mathrm{~L}_{\mathrm{LH} 12}, \mathrm{~L}_{\mathrm{LH} 21}$ and $\mathrm{L}_{\mathrm{LH} 22}$ are generated because of the input and output stubs shorted to the ground plane 2. The shunt right handed capacitances $\mathrm{C}_{\mathrm{RH} 11}, \mathrm{C}_{\mathrm{RH} 12}, \mathrm{C}_{\mathrm{RH} 21}$ and $\mathrm{C}_{\mathrm{RH} 22}$ are introduced due to the

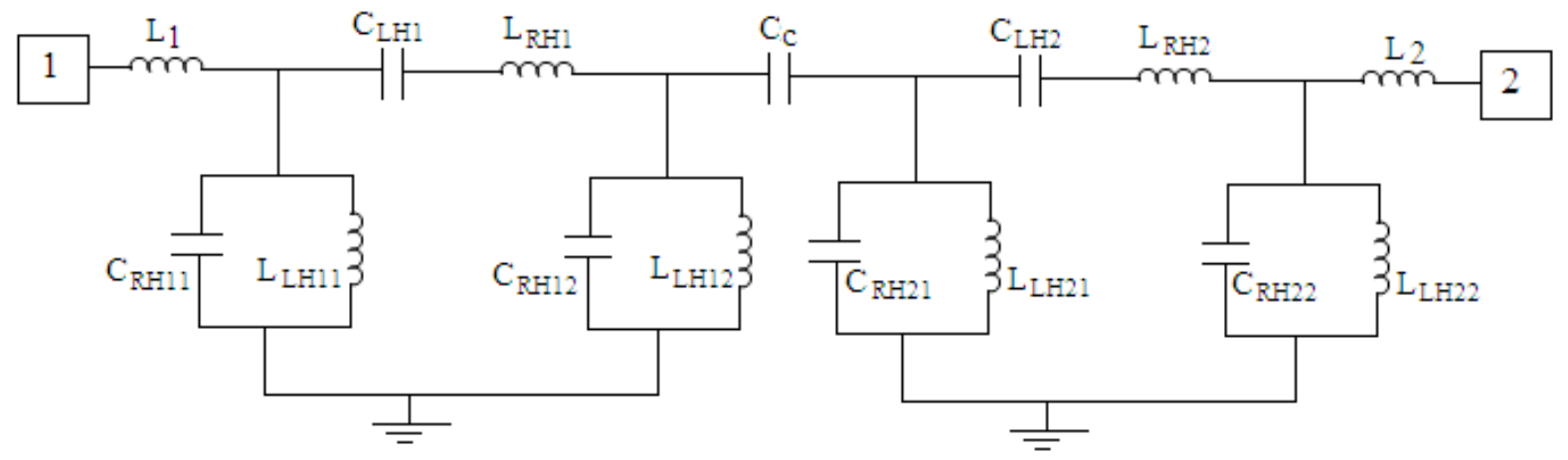

Fig. 10. Equivalent lumped circuit model of the proposed UWB BPF shown in Fig. 1

TABLE II. COMPONENTS VALUES OF THE EQUIVALENT LUMPED CIRCUIT MODEL SHOWN IN FIG. 10

\begin{tabular}{|l|c|c|c|c|}
\hline Component & $\mathrm{L}_{1}$ & $\mathrm{~L}_{2}$ & $\mathrm{~L}_{\mathrm{RH} 1}$ & $\mathrm{~L}_{\mathrm{RH} 2}$ \\
\hline Value $(\mathrm{nH})$ & 0.1 & 0.3 & 1.25 & 1.24 \\
\hline Component & $\mathrm{L}_{\mathrm{LH} 11}$ & $\mathrm{~L}_{\mathrm{LH} 12}$ & $\mathrm{~L}_{\mathrm{LH} 21}$ & $\mathrm{~L}_{\mathrm{LH} 22}$ \\
\hline Value $(\mathrm{nH})$ & 1.25 & 1.1 & 1.7 & 1.3 \\
\hline Component & $\mathrm{C}_{\mathrm{LH} 1}$ & $\mathrm{C}_{\mathrm{LH} 2}$ & $\mathrm{C}_{\mathrm{RH} 11}$ & $\mathrm{C}_{\mathrm{RH} 12}$ \\
\hline Value $(\mathrm{pF})$ & 0.5 & 0.55 & 0.5 & 9.45 \\
\hline Component & $\mathrm{C}_{\mathrm{RH} 21}$ & $\mathrm{C}_{\mathrm{RH} 22}$ & $\mathrm{C}_{\mathrm{C}}$ & \\
\hline Value $(\mathrm{pF})$ & 0.3 & 0.55 & 1.4 & \\
\hline
\end{tabular}


parasitic effects of shorted stubs to ground plane 2 and the gap $\left(\mathrm{W}_{5}-\mathrm{W}_{4}\right)$ between topmost additional finger of IDC to the ground plane 1. The various components values of the equivalent lumped circuit model shown in Fig. 10 are listed in Table II.

The comparative S-parameters versus frequency response of EM simulation and circuit model are illustrated in Fig. 11. The EM simulation results are taken corresponding to the optimized physical parameters listed in Table I. The close similarity between the EM simulation and circuit model results are observed, however a slight deviation between the two may be seen which may arise because of the ignorance of mutual coupling between the individual circuit elements. The $-3.0 \mathrm{~dB}$ insertion-loss frequency bands for EM simulation and circuit model are found to be $3.3 \mathrm{GHz}$ to $13.0 \mathrm{GHz}$ and 3.2 $\mathrm{GHz}$ to $13.1 \mathrm{GHz}$ respectively. The passband insertion-loss is less than $0.5 \mathrm{~dB}$ and $0.25 \mathrm{~dB}$ respectively and reflection-loss greater than $11.2 \mathrm{~dB}$ and $10.9 \mathrm{~dB}$ respectively for EM simulation and circuit model. The EM simulation results show the good stopband rejection $\left(\left|S_{21}\right|>20 \mathrm{~dB}\right.$ and $\left|S_{11}\right|<$ $0.8 \mathrm{~dB}$ ) from $13.6 \mathrm{GHz}$ to $15 \mathrm{GHz}$ and steep roll-off from passband to stopband. The fractional bandwidth of the filter is found to be $119 \%$.

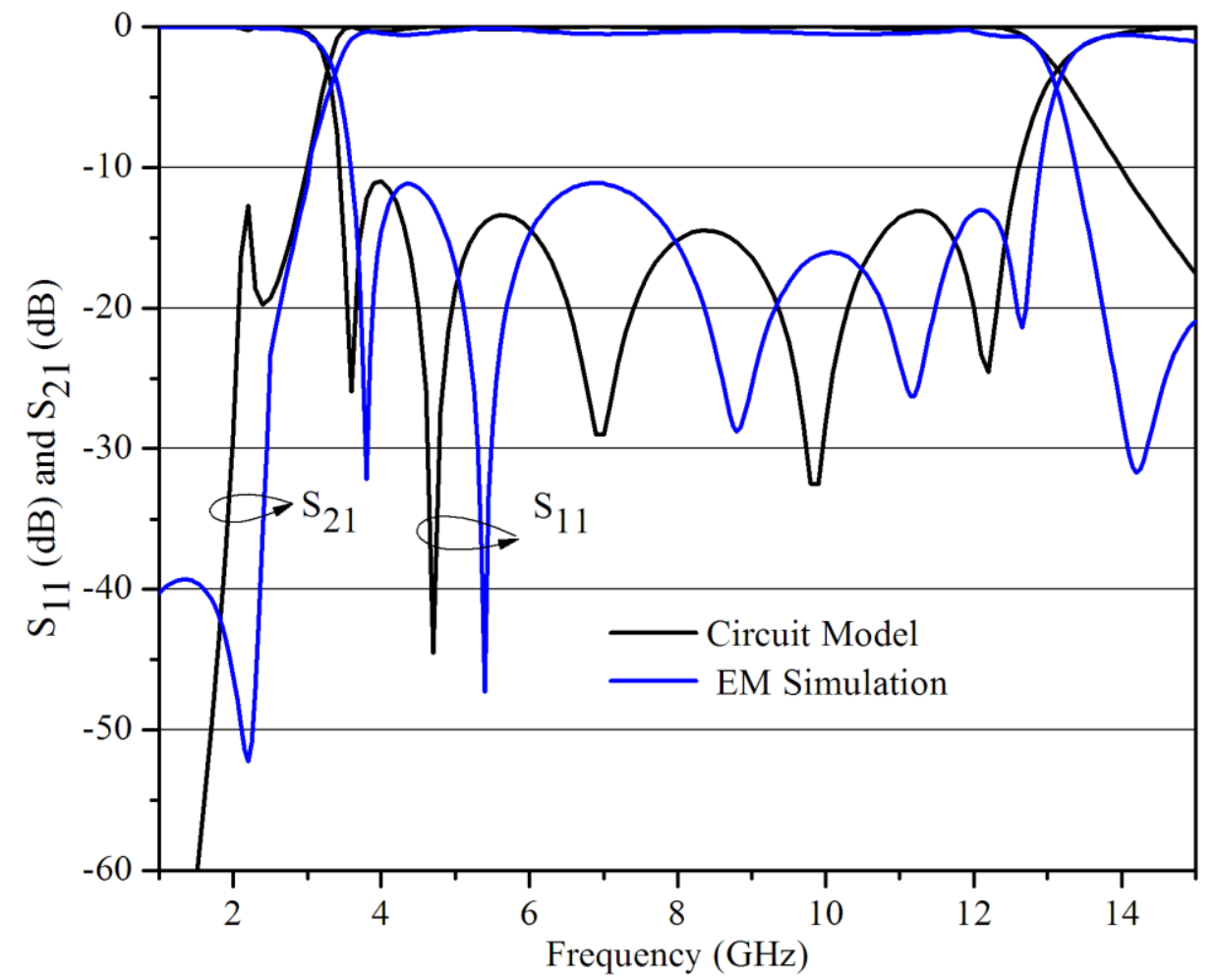

Fig. 11. Comparative S-parameters vs. Frequency plot of equivalent circuit model and EM simulation

\section{MEASUREMENT RESULTS AND DISCUSSION}

Based on the optimized physical parameters listed in Table I, the proposed UWB BPF shown in Fig. 1 is fabricated and its performance parameters are measured using Agilent vector network analyzer. Fig. 12 shows the photograph of fabricated prototype of proposed UWB BPF. The comparative simulated and measured S-parameters versus frequency response are shown in Fig. 13. From the Fig. 13, a close similarity between the simulated and measured results can be observed. 
Moreover a little deviation between the simulated and measured results can be seen, which mainly arise because of the finite ground plane, improper soldering and fabrication tolerances. The measured $-3.0 \mathrm{~dB}$ insertion-loss frequency band of the proposed UWB BPF is found to be $3.12 \mathrm{GHz}$ to 12.43 $\mathrm{GHz}$, whereas the simulated $-3.0 \mathrm{~dB}$ insertion-loss frequency band is found to be $3.3 \mathrm{GHz}$ to 13.0 GHz. In throughout the passband, the measured and simulated insertion-losses are less than $0.6 \mathrm{~dB}$ and $0.5 \mathrm{~dB}$ respectively, whereas return-losses are more than $10.4 \mathrm{~dB}$ and $11.2 \mathrm{~dB}$ respectively. The mesured fractional bandwidth of the filter is found to be $120 \%$.

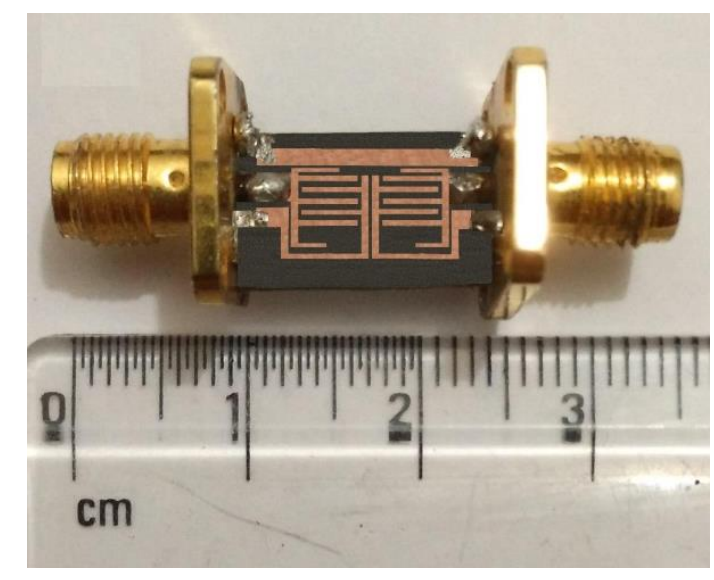

Fig. 12. Prototype of fabricated proposed UWB BPF

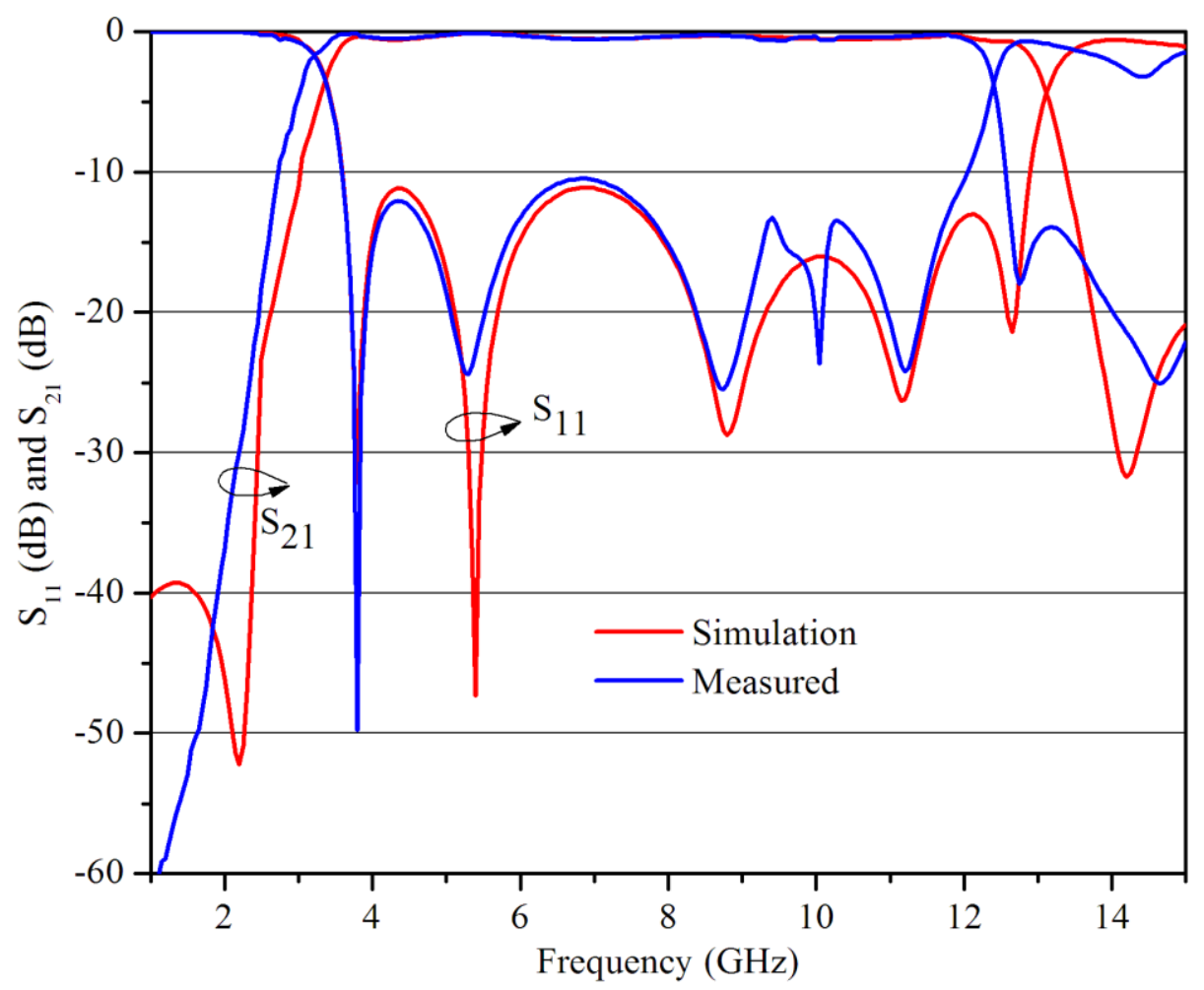

Fig. 13. Comparative simulated and measured S-parameters vs. Frequency plot

The simulated and measured group delay versus frequency response of the proposed ultra wideband bandpass filter is depicted in Fig. 14. The low and constant group delay response can be observed throughout the passband of UWB BPF. The simulation and measured group delay vary between the $0.7 \mathrm{~ns}$ to $1.5 \mathrm{~ns}$ and $0.76 \mathrm{~ns}$ to $1.74 \mathrm{~ns}$ respectively, hence the maximum variation of simulated and 
measured group delays are $0.80 \mathrm{~ns}$ and $0.98 \mathrm{~ns}$ respectively. However, relatively large variation of group delays in both, simulation and measured results may be observed at both ends of the passband, which arises because of the sharp transition of insertion-loss curve from passband to stopband. The large difference between the simulated and experimental results at frequency $2.6 \mathrm{GHz}$ may be seen because of the fabrication tolerances and improper soldering during the development of the UWB BPF.The low and flat group delay response throughout the operating passband frequency band shows the good time domain response of the filter. Comparative EM simulated, equivalent lumped circuit model and measured performance of the proposed UWB BPF are listed in Table III. The physical parameters, fabrication complexities and performance of the proposed UWB BPF are compared in Table IV with the ealrier reported UWB BPFs.

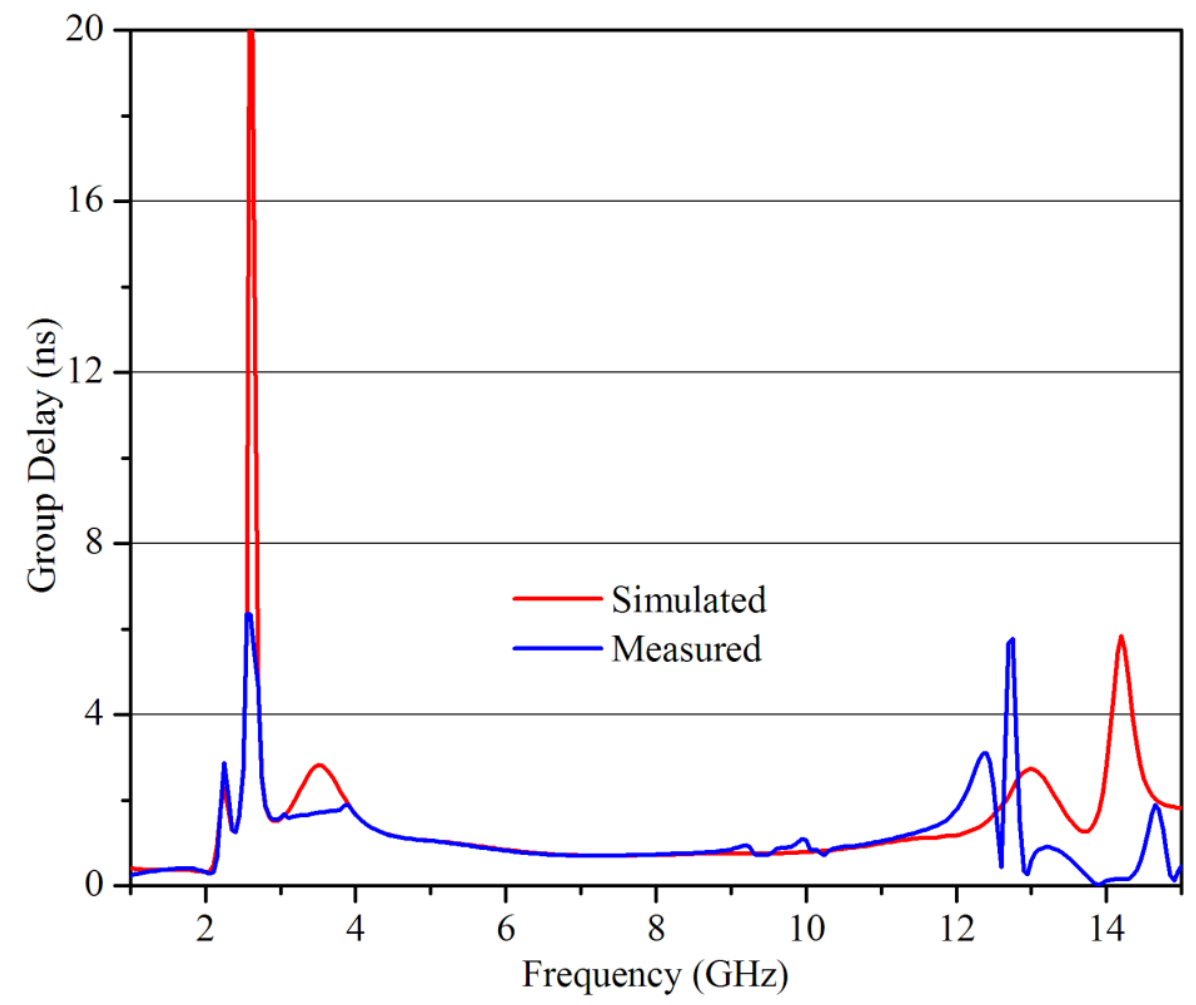

Fig. 14. Comparative simulated and measured group delay vs. Frequency plot

TABLE III. COMPARISON OF EM SIMULATION, CIRCUIT MODEL AND MEASURED RESULTS

\begin{tabular}{|c|c|c|c|c|c|c|}
\hline Parameters & $\left|\mathrm{S}_{11}\right| \mathrm{dB}$ & $\left|\mathrm{S}_{21}\right| \mathrm{dB}$ & $\begin{array}{c}\text { Frequency range } \\
(\mathrm{GHz})\end{array}$ & $\begin{array}{c}\text { Bandwidth } \\
(\mathrm{GHz})\end{array}$ & $\begin{array}{c}\text { FBW } \\
(\%)\end{array}$ & $\begin{array}{c}\text { Group delay } \\
(\mathrm{ns})\end{array}$ \\
\hline Simulated & 11.2 & 0.5 & $3.3-13.0$ & 9.7 & 119 & 0.80 \\
\hline Circuit Model & 10.9 & 0.25 & $3.2-13.1$ & 9.9 & 121 & -- \\
\hline Measured & 10.4 & 0.6 & $3.12-12.43$ & 9.31 & 120 & 0.98 \\
\hline
\end{tabular}


TABLE IV. COMPARISON OF PROPOSED UWB BPF WITH THE VARIOUS REPORTED UWB BPF

\begin{tabular}{|l|l|l|l|l|l|l|}
\hline Ref. & $\begin{array}{l}\left|\mathrm{S}_{21}\right| \\
(\mathrm{dB})\end{array}$ & $\begin{array}{l}\left|\mathrm{S}_{11}\right| \\
(\mathrm{dB})\end{array}$ & $\begin{array}{l}\text { Frequency } \\
\text { Range }(\mathrm{GHz})\end{array}$ & $\begin{array}{l}\text { Size } \\
(\mathrm{mm})\end{array}$ & $\begin{array}{l}\text { Area } \\
\left(\mathrm{mm}^{2}\right)\end{array}$ & Via \\
\hline$[3]$ & 0.5 & 11 & $2.9-10.75$ & $16.8 \times 4.8$ & 80.64 & Yes \\
\hline$[4]$ & 1.0 & 13 & $3.1-10.6$ & $13 \times 8.5$ & 110.5 & Yes \\
\hline$[5]$ & 1.0 & 10 & $4.0-9.5$ & $30 \times 8.5$ & 255 & Yes \\
\hline$[6]$ & 0.3 & 10 & $3.15-10.8$ & $18.4 \times 4.5$ & 82.8 & No \\
\hline$[7]$ & 1.5 & 10 & $3.9-10.3$ & $30 \times 15$ & 450 & Yes \\
\hline$[8]$ & 1.1 & 15.2 & $2.5-11$ & $30 \times 20$ & 600 & No \\
\hline$[9]$ & 1.0 & 14 & $2.8-10.9$ & $30 \times 20$ & 600 & Yes \\
\hline$[10]$ & 2.5 & 15 & $0-18$ & $26.2 \times 11.9$ & 311.78 & No \\
\hline$[11]$ & 1.35 & 13 & $3.1-10.6$ & $13 \times 7.8$ & 101.4 & Yes \\
\hline$[12]$ & 1.0 & 13 & $2.96-10.43$ & $42.3 \times 12.3$ & 520.3 & Yes \\
\hline$[13]$ & 0.68 & 17 & $3.4-10.7$ & $21 \times 5.3$ & 111.3 & Yes \\
\hline $\begin{array}{l}\text { This } \\
\text { work }\end{array}$ & 0.6 & 10.4 & $3.12-12.43$ & $11.9 \times 6$ & 71.4 & No \\
\hline
\end{tabular}

\section{CONCLUSION}

Design and development of a compact CRLH TL based UWB BPF is presented in this paper. The CRLH TL is designed on coupling of two unit-cells of via-less CRLH TL. The filter is compact in size $11.9 \times 6 \mathrm{~mm}^{2}$ and excited by the CPW-fed. Due of the absence of via the filter ease the fabrication process and saves the time taken to build the vias. The developed UWB BPF shows the measured insertion-loss less than $0.6 \mathrm{~dB}$ and return-loss more than $10.4 \mathrm{~dB}$ throughout the passband $3.12 \mathrm{GHz}-12.43 \mathrm{GHz}$ with fraction bandwidth of $120 \%$. Moreover, filter also shows the low (maximum deviation of $0.98 \mathrm{~ns}$ ) and flat group delay response throughout the passband. Because of the compact in size and good in performance the proposed UWB BPF may find the potential applications in modern small sized wireless communication systems.

\section{REFERENCES}

[1] A. Lai, C. Caloz, and T. Itoh, "Composite right/left-handed transmission line metamaterials," IEEE Microwave Mag. 5, vol. 5, pp. 34-50, 2004.

[2] Revision of Part 15 of the commission's rules regarding ultra- wideband transmission system, "ET-Docket 98-153, First note and order, Federal Communication Commission," Feb 2002.

[3] K.U. Ahmed and B.S. Virdee, "Ultra-wideband bandpass filter based on composite right/left handed transmissionline unit-cell,” IEEE Trans Microwave Theory Tech, vol. 61, pp. 782-788, 2013.

[4] A. Alburaikan, M. Aqeeli, X. Huang, and Z. Hu, "Miniaturized ultra-wideband bandpass filter based on CRLH-TL unit cell," In: Microwave Conference (EuMC), Rome, Italy, pp. 540-543, 2014.

[5] Fitri Yuli Zulkifli, Andik Atmaja and Eko Tjipto Rahardjo, "Implementation of single cell composite right-left handed transmission line for ultra wideband bandpass filter," International Journal of Technology (IJTech), vol. 2, pp. 121-128, 2012.

[6] Nilotpal and Dileep Kumar Upadhyay, "A compact UWB bandpass filter based on CRLH via-less CPW-fed," Microwave and Optical Technology Lett, vol. 58, pp. 276-279, 2016.

[7] B. Qian, D. Jun, and G. Chen Jiang, "New design of ultra wideband filter using interdigitated coupled lines CRLHTL structure," In: 2012 10th International Symposium on Antennas, Propagation \& EM Theory (ISAPE), Xian, China, pp. 486-489, 2012 
[8] Xu, H.-X., Wang, G.-M., and Zhang, C.-X., "Fractal-shaped UWB bandpass filter based on composite right/left handed transmission line," Elect. Lett., vol. 46, no.4, pp. 285-287, 2010.

[9] A.M. Abbosh, "Ultra wideband balanced bandpass filter," IEEE Microwave Wireless Components Lett., vol. 21, 480-482, 2011

[10] B. Xia, L.-S. Wu, and J. F. Mao, "An ultra-wideband balanced bandpass filter based on defected ground structures," Progress In Electromag. Research C, vol. 25, 133-144, 2012

[11] Huang, J.-Q. and Q.-X. Chu, "Compact UWB band-pass filter utilizing modified composite right/left-handed structure with cross coupling," Progress In Electromag. Research, vol. 107, pp. 179-186, 2010.

[12] Tang, C.-W., and Chen, M.-G., "A microstrip ultra-wideband bandpass filter with cascaded broadband bandpass and bandstop filters," IEEE Trans Microwave Theory Tech, vol. 55, pp. 2412-2418, 2007

[13] Zhang, Z., and Xiao, F., “An UWB bandpass filter based on a novel type of multi-mode resonator," IEEE Microwave Wireless Compon Lett, vol. 22, 506-508, 2012 